\title{
Nilotinib Induces ER Stress and Cell Death in H9c2 Cells
}

\author{
D. LEKES ${ }^{1}$, I. SZADVARI ${ }^{1}$, O. KRIZANOVA ${ }^{1,2}$, K. LOPUSNA $^{3}$, I. REZUCHOVA ${ }^{3}$, \\ M. NOVAKOVA ${ }^{1,4}$, Z. NOVAKOVA ${ }^{1}$, T. PARAK ${ }^{5}$, P. BABULA ${ }^{1,4}$
}

${ }^{1}$ Department of Physiology, Faculty of Medicine, Masaryk University, Brno, Czech Republic, ${ }^{2}$ Institute of Clinical and Translational Research, Biomedical Research Center, Slovak Academy of Sciences, Bratislava, Slovakia, ${ }^{3}$ Institute of Virology, Biomedical Research Center, Slovak Academy of Sciences, Bratislava, Slovakia, ${ }^{4}$ International Clinical Research Center, St. Anne's University Hospital Brno, Brno, Czech Republic, ${ }^{5}$ Department of Human Pharmacology and Toxicology, Faculty of Pharmacy, University of Veterinary and Pharmaceutical Sciences Brno, Brno, Czech Republic

Received September 20, 2016

Accepted October 10, 2016

\section{Summary}

Tyrosine kinases inhibitors (TKi) represent a relatively novel class of anticancer drugs that target cellular pathways overexpressed in certain types of malignancies, such as chronic myeloid leukaemia (CML). Nilotinib, ponatinib and imatinib exhibit cardiotoxic and vascular effects. In this study, we focused on possible cardiotoxicity of nilotinib using $\mathrm{H} 9 \mathrm{c} 2$ cells as a suitable cell model. We studied role of endoplasmic reticulum (ER) stress and apoptosis in nilotinib toxicity using a complex approach. Nilotinib impaired mitochondrial function and induced formation of ROS under clinically relevant concentrations. In addition, ability of nilotinib to induce ER stress has been shown. These events result in apoptotic cell death. All these mechanisms contribute to cytotoxic effect of the drug. In addition, involvement of ER stress in nilotinib toxicity may be important in co-treatment with pharmaceuticals affecting ER and ER stress, e.g. beta-blockers or sartans, and should be further investigated.

\section{Key words}

Apoptosis • Cardiotoxicity • ER stress • Nilotinib • Reactive oxygen species

\section{Corresponding author}

P. Babula, Department of Physiology, Faculty of Medicine, Masaryk University, Kamenice 5, 62500 Brno, Czech Republic and International Clinical Research Center, St. Anne's University Hospital Brno, 65691 Brno, Czech Republic. E-mail: babula@med.muni.cz

\section{Introduction}

Chronic myeloid leukaemia (CML) is a hematological malignity commonly caused by a reciprocal chromosomal translocation between chromosome 9 and 22 (Philadelphia chromosome, $\mathrm{Ph}$ ) (Lambert et al. 2013, Sirvent et al. 2008). The breakpoint cluster region $(B C R)$ gene is juxtaposed to $A B L$ gene for ABL1 kinase and this new fusion gene $(B C R-A B L)$ encodes an unregulated, constitutively expressed and active cytoplasm-targeted tyrosine kinase that allows the myeloid cells to proliferate without being regulated by cytokines (Lambert et al. 2013, Sirvent et al. 2008). Due to this fact, BCR-ABL has been established as a highly attractive target for drug intervention. BCR-ABL tyrosine kinase inhibitors (TKi) represent a relatively novel class of anticancer drugs targeted on pathological cellular pathways overexpressed in certain

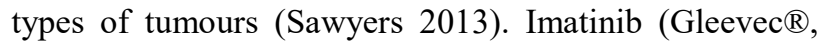
Novartis) was the first TKi introduced in 1992 and approved by the FDA for the treatment of CML (Deininger et al. 2005). Shortly after its introduction, development of resistance exemplified by the lack of efficacy at clinical dose and resurgence of the disease have occurred in some patients (Sawyers 2003b, Weisberg and Griffin 2001). To overcome problems with resistance and improve tolerance, next generation of $\mathrm{TKi}$ has been developed. The most important TKi of the second generation are nilotinib (Tasigna ${ }^{\circledR}$, AMN107), 
dasatinib (Sprycel $\AA$, BMS-354825), bosutinib (Bosulif $\AA$, SKI-606) and bafetinib (INNO-406, NS-187, CNS-9). The newest TKi, ponatinib (Iclusig ${ }^{\mathrm{TM}}$, AP24534), is classified as the third generation of TKi. Nilotinib and dasatinib are approved in the Czech Republic for the treatment of newly diagnosed patients as well as imatinib-resistant CML. Bosutinib and ponatinib are approved for the treatment of imatinib- and other TKi-resistant or intolerant CML.

During discovery and development of new therapeutic drugs, potential toxicity to humans should be minimized. In comparison to "classic" antitumorous drugs, toxicity of TKi is lower. However, BCR-ABL is not the sole tyrosine kinase inhibited by TKi. Other tyrosine kinase pathways are affected in myeloid cells and in other tissues, as well (Takahashi 2011). Some of these pathways have been identified as being important for maintaining the viability of cells in normal tissues, such as the heart (He et al. 2015, Jaffre et al. 2012). This interference may result in various side effects, including neutropenia and thrombocytopenia. One of the recognized side effects is cardiotoxicity, which can be manifested by a broad range of signs and symptoms connected with deterioration of heart function and alteration of its structure. The most common manifestations of TKi cardiotoxicity include, but are not limited to, conduction impairment, such as QT interval prolongation, multifocal cardiomyocyte necrosis or apoptosis, myocardial fibrosis, myocardial hypertrophy and dilatation resulting in impaired cardiac contractility (Yang and Papoian 2012). TKi interfere primarily with pathways mediating the mitotic growth of tumour cells (Krause and Van Etten 2005). However, the mechanisms behind these events and the relations between signalling pathways and cardiovascular side effects of the TKi are largely unclear. For example, Kerkela and co-workers have reported individuals who developed severe congestive heart failure while receiving imatinib; moreover, it was shown that imatinib-treated mice developed left ventricular contractile dysfunction (Kerkela et al. 2006). The authors demonstrated also mitochondrial abnormalities and accumulation of membrane whorls in both vacuoles and the sarco-(endo-) plasmic reticulum. In addition, cardiomyocytes showed activation of the endoplasmic reticulum (ER) stress response, collapse of the mitochondrial membrane potential, release of cytochrome $\mathrm{c}$ into the cytosol, reduction in cellular ATP content, and cell death. Ability of TKi to create reactive oxygen species (ROS) and interfere with ion channels, especially hERG channel has to be considered in cardiotoxic action of TKi. Data about the ability of TKi to induce ROS generation are still limited. Nilotinib and ponatinib have shown the ability to generate ROS in human cardiac myocytes (Doherty et al. 2013). Moreover, nilotinib (Hazarika et al. 2008) and dasatinib (Johnson et al. 2010), but not bosutinib (Abbas et al. 2012), have demonstrated significant ability to prolong the QT interval in patients. Data on ponatinib are ambiguous and mechanism of QT interval prolongation remains almost unknown. We can assume the ability of TKi to change hERG channel activity resulting in alteration in the electrophysiological properties, including action potential duration and cell excitability, in the human heart (Shah et al. 2013). Nilotinib exposure is also closely associated with severe peripheral arterial occlusive disease (PAOD), mainly in patients older than 60 years, or with cardiovascular risk factor such as hypercholesterolemia, arterial hypertension, overweight/obesity, smoking or diabetes mellitus (Bondon-Guitton et al. 2016). However, detailed clinical relevant data are still missing or are inadequate.

In the light of above-mentioned, further detailed studies on cardiotoxicity of BCR-ABL TKi and its mechanisms are highly needed for their effective pharmacovigilance and on-going reassessment of their risk and benefit. Revealing the mechanisms of cardiotoxicity and cardiac dysfunction is necessary to propose practicable prevention of these side effects. In our study, we focused on the effect of nilotinib on H9c2 cells, a subclone of the original clonal cell line derived from embryonic BD1X rat heart tissue, with special attention to ER stress and apoptosis.

\section{Methods}

\section{Reagents}

Culture media and chemicals were purchased from Sigma-Aldrich, USA, unless noted otherwise. All probes and kits for visualizations were obtained from Invitrogen, USA.

\section{Cell line}

The H9c2 cell line, originally derived from embryonic rat heart tissue using selective serial passages, was used in our experiments. Cells were cultured in DMEM supplemented with $1.5 \mathrm{~g} / 1$ sodium bicarbonate, $10 \%$ fetal bovine serum, $100 \mathrm{U} / \mathrm{ml}$ of penicillin, and $100 \mu \mathrm{g} / \mathrm{ml}$ of streptomycin at $37^{\circ} \mathrm{C}$ in a humidified 
atmosphere of $5 \% \mathrm{CO}_{2}$. Cells were subcultured when reached $70-80 \%$ confluence. For the experiments, cells were seeded in 24-well plates. After seeding, cells were allowed to grow for 1 day to reach the desired confluence (>75-80\%). Treatments with nilotinib (Abcam, Czech Republic) in a concentration range from 0 to $15 \mu \mathrm{M}$ lasted for $0-48 \mathrm{~h}$ (intervals $24 \mathrm{~h}$ and $48 \mathrm{~h}$ ). DMSO was used as a second control. Then, cells were washed thrice with PBS, harvested and analyzed immediately.

\section{Cell viability and morphology}

Viability of $\mathrm{H} 9 \mathrm{c} 2$ cells was determined using fluorescein diacetate/propidium iodide (FDA/PI) dual staining (Kong and Rabkin 2000). Cells were observed by epifluorescence microscopy using Nikon Eclipse Ti-S/L100 (Nikon, Japan). NIS elements software (Nikon, Japan) was used to process images and to evaluate the resultant pictures (cell area). Resazurin assay (In Vitro Toxicology Assay Kit, Resazurin based, SigmaAldrich, USA) was used to confirm microscopic observations (Moreira et al. 2014).

\section{Determination of intracellular ROS}

ROS-ID ${ }^{\circledR}$ Total ROS/Superoxide detection kit (Enzo Biochem, USA) was used to quantify total ROS according to manufacturer's instructions. In addition, production of total ROS was confirmed using visualization by CellROX Green reagent according to manufacturer's instructions.

\section{Determination of ER stress markers}

In order to determine ER stress, Thioflavin T (ThT) at a final concentration $5 \mu \mathrm{M}$ was used according to procedure described by Beriault and Werstuck
(Beriault and Werstuck 2013). ER-Tracker Red in combination with Hoechst 33258 and acridine orange was used to visualize ER. In order to evaluate level of $A T F 4$, $C H O P$, and $X B P 1$ expression, isolation of total RNA, DNase treatment and cDNA synthesis, and real-time PCR assay were performed. Total RNA from cells was extracted and purified using TRIzol reagent and treated with DNase I to eliminate any DNA contamination. The reaction mixture contained $1 \mu \mathrm{g}$ of total RNA, $1 \mathrm{U}$ of DNase I, RNase-free (Novagen, Germany) and 1x M-MLV Reaction Buffer in a final volume of $10 \mu \mathrm{l}$. DNase I treatment was performed for 3 hours at $37^{\circ} \mathrm{C}$. DNase I enzyme activity was stopped by $1 \mu \mathrm{l}$ of $25 \mathrm{mM}$ EDTA, followed by incubation at $65^{\circ} \mathrm{C}$ for $15 \mathrm{~min}$. The purity of each RNA sample was controlled by qPCR specific for Cyclophilin A. Reverse transcription of pure RNA to complementary DNA was performed by ReadyTo-Go You-Prime First-Strand Beads (GE Healthcare, UK) according to the instructions of manufacturer. Prepared cDNA was stored at $-20{ }^{\circ} \mathrm{C}$ until further use. The level of mRNA expression of ATF4, CHOP, XBP1 and housekeeping gene Cyclophilin $A$ was quantified using Luminaris HiGreen qPCR Master Mix, high ROX (ThermoFischer Scientific, USA). Primers used for qPCR are listed in Table 1. The qPCR mixture included $0.6 \mu \mathrm{mol} / 1$ of each primer and $1.7 \mu \mathrm{l}$ of cDNA in the final volume of $10 \mu \mathrm{l}$. The qPCR was carried out in a thermocycler Applied Biosystems StepOne ${ }^{\mathrm{TM}}$ RealTime PCR Systems (Applied Biosystems, USA; $50{ }^{\circ} \mathrm{C} / 2 \mathrm{~min}, \quad 95^{\circ} \mathrm{C} / 10 \mathrm{~min}$, and $40 \mathrm{x} \quad\left(95^{\circ} \mathrm{C} / 15 \mathrm{~s}\right.$, $\left.60{ }^{\circ} \mathrm{C} / 60 \mathrm{~s}\right)$ ). Each qPCR reaction was run in triplicates at the same time with qPCR without template (negative control). Relative gene expression was determined by Applied Biosystems StepOne ${ }^{\mathrm{TM}}$ software v2.2.2.

Table 1. List of primers.

\begin{tabular}{|c|c|c|c|}
\hline Gene & Location & Sequence $\left(5^{\prime}-3^{\prime}\right)$ & Product size \\
\hline $\begin{array}{l}\text { Cyclophilin A } \\
\text { (GI: 203701) }\end{array}$ & $\begin{array}{l}151-174 \\
424-450\end{array}$ & $\begin{array}{l}\text { F: CGTGCTCTGAGCACTGGGGAGAAA (Krizanova et al. 2014) } \\
\text { R: CATGCCTTCTTTCACCTTCCCAAAGAC (Krizanova et al. 2014) }\end{array}$ & 300 bp \\
\hline $\begin{array}{l}\text { ATF4 } \\
\text { (GI: } 563407075)\end{array}$ & $\begin{array}{l}144-163 \\
283-300\end{array}$ & $\begin{array}{l}\text { F: GTGGCCAAGCACTTCAAACC (Corazzari et al. 2007) } \\
\text { R: CCCGGAGAAGGCATCCTC (Corazzari et al. 2007) }\end{array}$ & 157 bp \\
\hline $\begin{array}{l}\text { XBP1 } \\
(\text { GI: } 51259532)\end{array}$ & $\begin{array}{l}92-110 \\
231-250\end{array}$ & $\begin{array}{l}\text { F: AGCGCTGCCGCTCATGCTTC (Krizanova et al. 2014) } \\
\text { R: TCTCGCGCAGTCTGTGCTGC (Krizanova et al. 2014) }\end{array}$ & 159 bp \\
\hline $\begin{array}{l}\text { СНОР } \\
\text { (GI: } 304282233)\end{array}$ & $\begin{array}{l}214-236 \\
595-618\end{array}$ & $\begin{array}{l}\text { F: GGAGCTGGAAGCCTGGTATGAGG (Kudo et al. 2008) } \\
\text { R: TCCCTGGTCAGGCGCTCGATTTCC (Kudo et al. 2008) }\end{array}$ & 402 bp \\
\hline
\end{tabular}




\section{Mitochondrial potential}

Mitochondrial potential was measured using JC-1 dye, where mitochondrial depolarization is indicated by a decrease in the red/green fluorescence intensity ratio. After incubation with the JC-1 staining solution at $37^{\circ} \mathrm{C}$ in the cell incubator for $10 \mathrm{~min}$, cells were washed twice with JC-1 staining buffer and analyzed using a fluorescence microplate reader (Cytation 3, BioTeK, USA). For microscopic analysis, $\mathrm{H} 9 \mathrm{c} 2$ cells were incubated in DMEM containing $3 \mu \mathrm{M}$ JC-1 for $30 \mathrm{~min}$ at room temperature in the dark. After staining, medium was removed; cells were washed twice with PBS, resuspended in a total volume of $200 \mu \mathrm{l}$ PBS and observed. Nikon Eclipse Ti-S/L100 (Nikon, Japan) and NIS elements software (Nikon, Japan) were used.

\section{TUNEL, Annexin V/PI, and caspase-like activity assays}

Annexin-V-FLUOS Staining Kit was used to visualize apoptic/late apoptic-necrotic cells. Nilotinibtreated cells were washed three times with ice-cold PBS (0.1 M, pH 7.4) and stained according to manufacturer's instructions. The results are expressed as a percentage of apoptotic and late apoptotic-necrotic cells, respectively. To label 3 '-OH end of DNA fragments, method of terminal transferase-mediated dUTP nick end-labeling (TUNEL) using In Situ Cell Death Detection Kit, Fluorescein (Promega, WI, USA) was used. Nuclei were counterstained with DAPI $(0.1 \mu \mathrm{g} / \mathrm{ml})$. The percentage of apoptotic cells was calculated as the ratio of the number of TUNEL-positive cells to the total number of DAPI-stained cells. CellEvent ${ }^{\mathrm{TM}}$ Caspase-3/7 Green Detection Reagent was used to determine activated caspase-3/7 in the cells according to manufacturer's instructions. Results are expressed as a percentage of caspase-3/7 positive cells. Cells were observed by epifluorescence microscopy using Nikon Eclipse Ti-S/L100 (Nikon, Japan); NIS elements software (Nikon, Japan) was used to process images and to evaluate the resultant pictures.

\section{Statistical analysis}

Data shown represent three independent experiments. Data are displayed as Mean \pm S.E.M. Comparison between untreated and treated groups was made using two-tailed unpaired Student's $t$-test. $P$ values of $\leq 0.05$ were considered statistically significant. Statistical significance is reported as either $\mathrm{P} \leq 0.05$, $\mathrm{P} \leq 0.01$.

\section{Results}

Nilotinib decreases cell viability and leads to changes in cell morphology

First, the effect of nilotinib on $\mathrm{H} 9 \mathrm{c} 2$ cells by FDA/PI and resazurin assays was determined. Cells were treated with increasing doses of nilotinib for $24 \mathrm{~h}$ and $48 \mathrm{~h}$, respectively. As shown in the Figure 1, nilotinib impaired viability in both concentration- and timedependent manners over the tested concentration range. Maximum reduction was observed at $15 \mu \mathrm{M}$ of nilotinib $(3.1 \pm 2.1 \%$ for $24 \mathrm{~h}$ and $0 \%$ for $48 \mathrm{~h})$. No changes were observed when the cells were treated with DMSO. These results were confirmed with resazurin assay (Fig. 1C). Changes in cell viability were accompanied with alterations in cell shape, including cell shrinkage (mainly at higher concentrations of nilotinib), vacuolization and blebbing (concentrations $0.1-2.5 \mu \mathrm{M}$ ) observed as a change in cell area (Fig. 1D). FDA/PI staining revealed changes in nuclear morphology, especially condensation of chromatin and signs of apoptosis (concentrations higher than $5 \mu \mathrm{M}$ ).

First, the effect of nilotinib on H9c2 cells by FDA/PI and resazurin assays was determined. Cells were treated with increasing doses of nilotinib for $24 \mathrm{~h}$ and $48 \mathrm{~h}$, respectively. As shown in the Figure 1, nilotinib impaired viability in both concentration- and timedependent manners over the tested concentration range. Maximum reduction was observed at $15 \mu \mathrm{M}$ of nilotinib $(3.1 \pm 2.1 \%$ for $24 \mathrm{~h}$ and $0 \%$ for $48 \mathrm{~h})$. No changes were observed when the cells were treated with DMSO. These results were confirmed with resazurin assay (Fig. 1C). Changes in cell viability were accompanied with alterations in cell shape, including cell shrinkage (mainly at higher concentrations of nilotinib), vacuolization and blebbing (concentrations $0.1-2.5 \mu \mathrm{M}$ ) observed as a change in cell area (Fig. 1D). FDA/PI staining revealed changes in nuclear morphology, especially condensation of chromatin and signs of apoptosis (concentrations higher than $5 \mu \mathrm{M}$ ).

\section{Nilotinib induces ROS generation and ER stress}

In order to study the effect of nilotinib on H9C2 cells, production of ROS was examined using two different methods. Exposure to nilotinib led to massive induction of ROS; it was more considerable after $48 \mathrm{~h}$ of nilotinib exposure, especially at 5,10 , and $15 \mu \mathrm{M}$ of nilotinib (17.8-fold increase after $24 \mathrm{~h}$ and 12.5-fold increase after $48 \mathrm{~h}$ for nilotinib at $15 \mu \mathrm{M}$, respectively). 

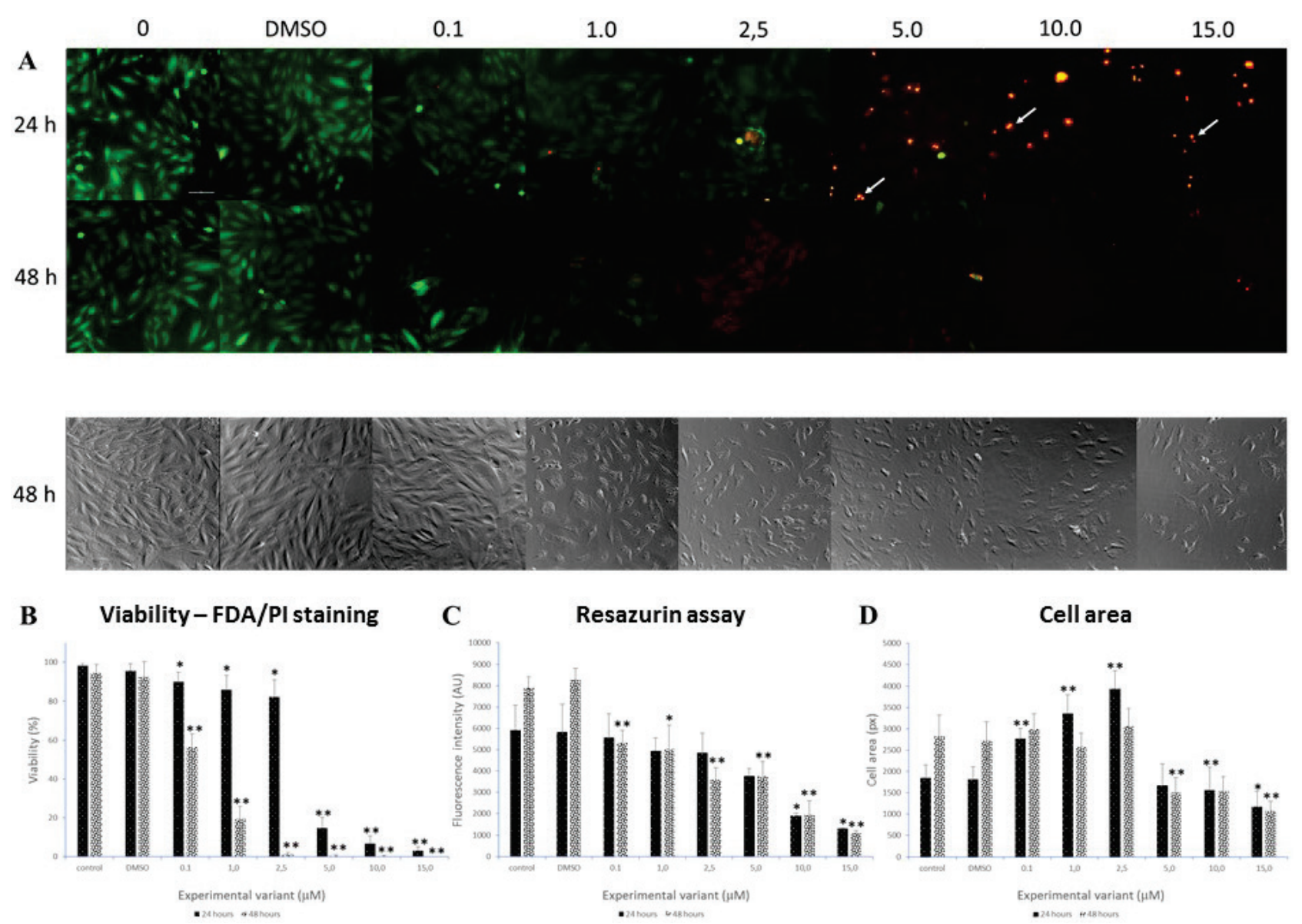

Fig. 1. Effect of nilotinib on viability and morphology of $\mathrm{H} 9 \mathrm{c} 2$ cells after 24 and $48 \mathrm{~h}$ of treatment (A). Viable cells show green fluorescence, dying or death cells show red fluorescence of nuclei. Note condensation of chromatin as a sign of apoptosis at concentrations higher than $5 \mu \mathrm{M}$ (white arrows). Significant changes are well evident in cell morphology. Viability expressed as percentage of viable cells (B) and as a result of resazurin assay (C). Changes in cell morphology determined as changes in cell surface (D). ${ }^{*} \mathrm{P} \leq 0.05,{ }^{* *} \mathrm{P} \leq 0.01$ using a two-tailed unpaired Student's t-test.

Details are in Figure 2A-B. Due to the fact that ER stress is one of the possible molecular mechanisms of toxicity, we studied whether nilotinib induces ER stress. We first detected changes in protein aggregation using ThT staining. Rapid increase in ER stress for concentrations higher that $1.0 \mu \mathrm{M}$ within $24 \mathrm{~h}$ was recorded (Fig. 3). 3.5-fold increase in protein aggregation was recorded for $2.5 \mu \mathrm{M}$ of nilotinib. ER stress was confirmed using

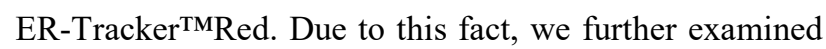
changes in expression of genes associated with ER stress - ATF4, CHOP and XBP1 (Fig. 3C-E). Significantly increased expression of all genes associated with ER stress was recorded after $24 \mathrm{~h}$ of nilotinib treatment. 3.5-fold increase in expression was determined for ATF4, 2.6-fold increase for $C H O P$ and 4.5 -fold increase for $X B P 1$. These results indicate that nilotinib induces expression of ER stress-related genes at the mRNA level, which is detectable after $24 \mathrm{~h}$ of treatment.
ROS and ER stress are involved in nilotinib-induced apoptosis

Apoptotic responses involve mitochondrial dysfunction. Therefore, we evaluated an impairment of mitochondrial functions by $\mathrm{JC}-1$, an indicator of mitochondrial membrane potential. ROS as well as prolonged ER stress are involved in mitochondrial dysfunction, too. We observed loss of mitochondrial membrane potential after 24-h treatment with nilotinib at all concentrations (Fig. 4C). Maximum loss was observed at $15 \mu \mathrm{M}$ of nilotinib $(7.2 \pm 4.1 \%$ versus $94.7 \pm 3.7 \%$ for control). These results were confirmed by microscopic observations (Fig. 4A). Caspase-3 is considered an executioner caspase and activates next caspases, including caspase-7. Cleavage or activity of caspase- 3 is the marker of apoptosis. We used fluorogenic substrate for activated caspase-3/7 in our experiments. Number of caspase-3/7-possitive cells increased in both concentration- and time-dependent-manner (Fig. 4B). 
Maximum number of positive cells was observed at high concentrations of nilotinib $(5,10$, and $15 \mu \mathrm{M})$ after $24-\mathrm{h}$ treatment, after 48-h treatment, number of positive cells significantly increased at low concentrations (up to $2.5 \mu \mathrm{M})$ and decreased at high concentrations (5, 10 and $15 \mu \mathrm{M}$ ) of nilotinib. Number of apoptotic (early apoptotic) and necrotic cells was evaluated using double Annexin V/PI staining after 24-h treatment (Fig. 4D). Maximum number of early apoptotic cells was observed at $10 \mu \mathrm{M}$ of nilotinib $(34.8 \pm 10.4 \%)$ and this number decreased at $15 \mu \mathrm{M}(22.7 \pm 4.9 \%)$. However, maximum number of necrotic cells was recorded for the highest concentration of nilotinib $(15 \mu \mathrm{M}, 57.2 \pm 8.9 \%)$. DNA fragmentation was evaluated using TUNEL assay (Fig. 4E). Number of TUNEL-positive cells increased significantly after 24-h treatment at all concentrations of nilotinib. The highest number of TUNEL-positive cells was recorded for $10 \mu \mathrm{M}$ of nilotinib $(26.8 \pm 4.7 \%)$ with slight decrease at the highest concentration $(15 \mu \mathrm{M}$, $23.7 \pm 7.6 \%$ ).
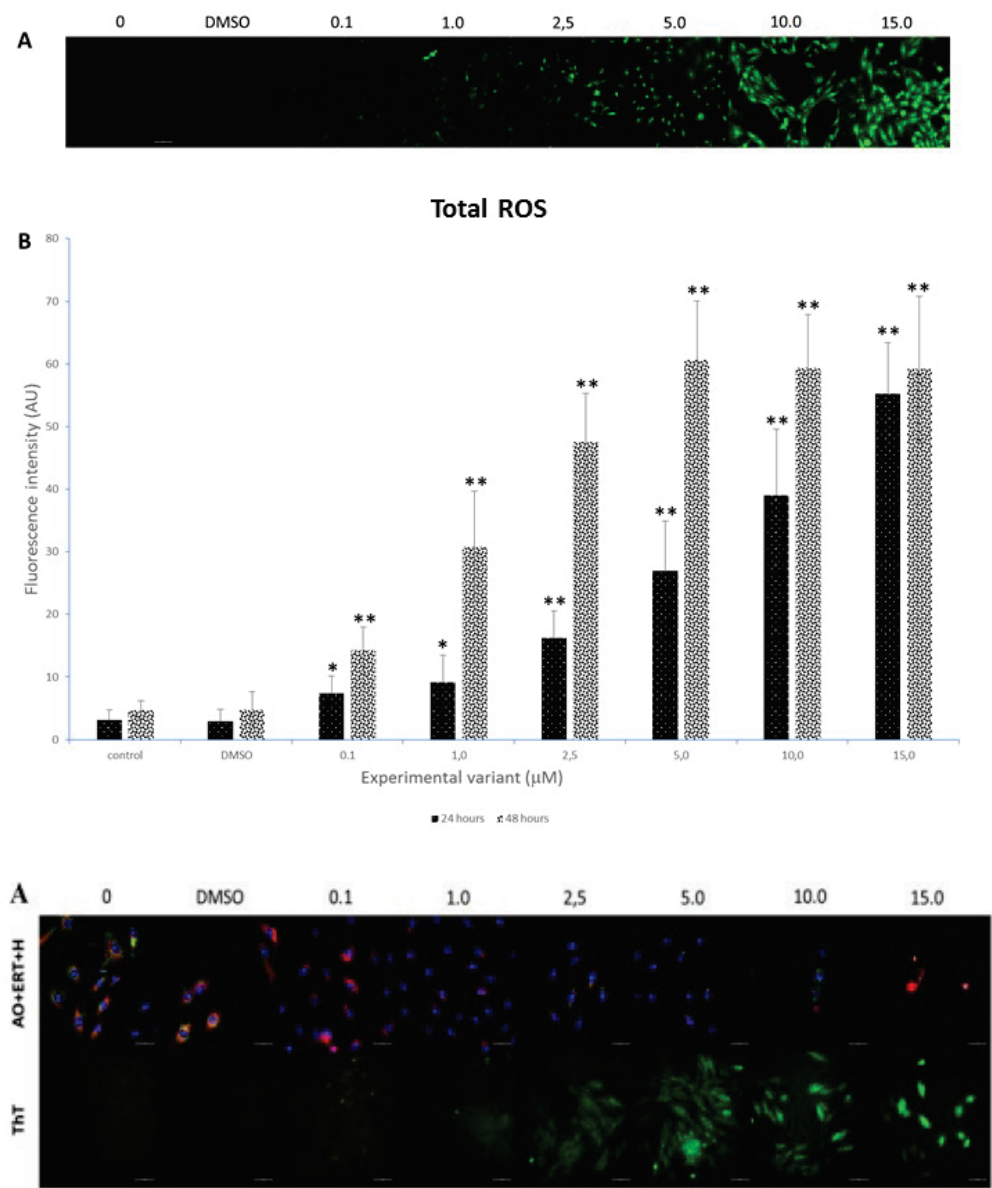

B

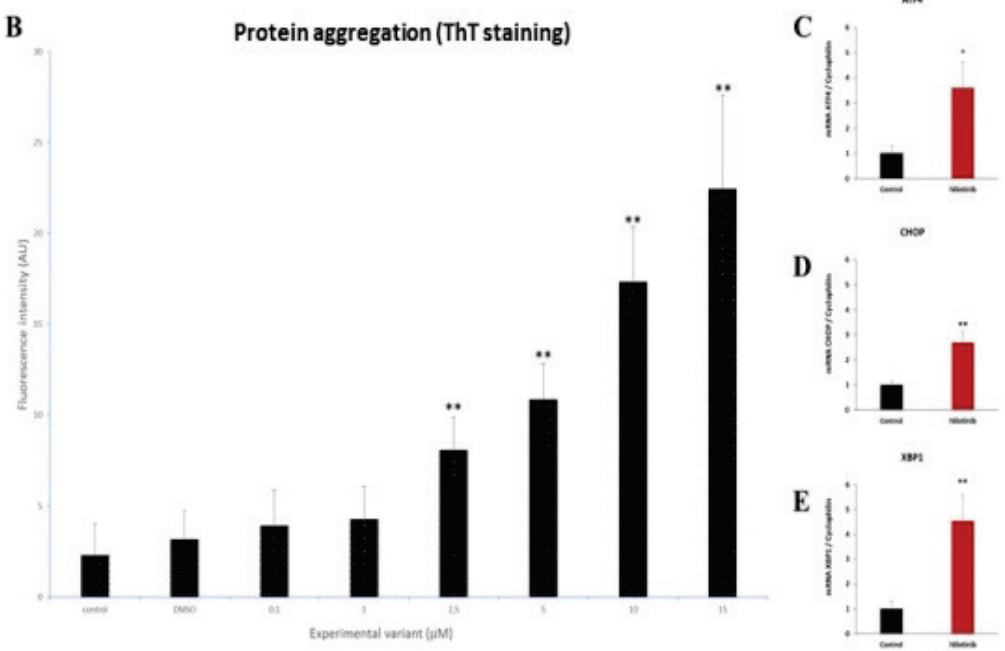

Fig. 2. Ability of nilotinib to generate ROS visualization of ROS after 24-h treatment using CellROX Green reagent (A). Intensity of fluorescence corresponds to amount of ROS. Amount of total ROS in concentration- and timedependent manners (B). ${ }^{*} \mathrm{P} \leq 0.05,{ }^{* *} \mathrm{P} \leq 0.01$ using a two-tailed unpaired Student's t-test.

Fig. 3. Ability of nilotinib to induce ER stress after $24 \mathrm{~h}$ of treatment. Visualization of ER using combination ER-Tracker Red/acridine orange/ Hoechst 33258 (A, upper row). Intensity of red fluorescence indicates ER function. Visualization of aggregation of proteins as a marker of ER stress and dysfunction (A, lower row). Thioflavin $T$ staining (ThT) was used. Increasing intensity of fluorescence indicates aggregates of proteins (B). Changes in expression of ATF4 (C), CHOP(D), and $X B P 1$ (E). ${ }^{*} \mathrm{P} \leq 0.05,{ }^{* *} \mathrm{P} \leq 0.01$ using a two-tailed unpaired Student's t-test. 

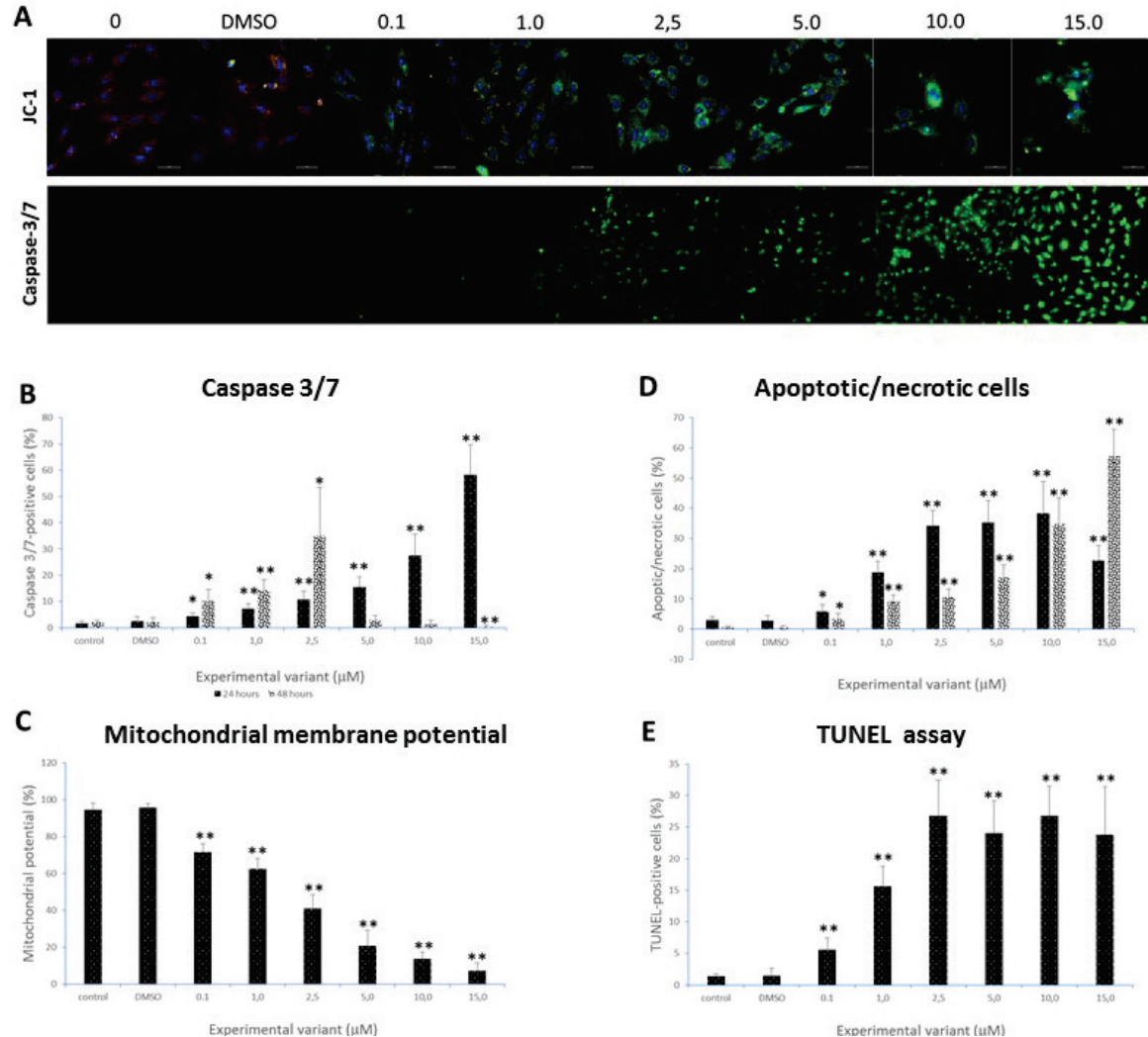

\section{Discussion}

Targeted cancer therapies have been designed to interact with particular proteins associated with tumour development or progression. Many of these agents are TKi. They target enzymes with dysregulated expression and which activity is associated with various tumours (Haouala et al. 2011). Current evidence suggests that TKi have potential cardiotoxic effects. All of the clinically available BCR-ABL inhibitors report the potential for cardiotoxicity in their respective package inserts (Orphanos et al. 2009). It has been shown that nilotinib can cause QT prolongation and sudden death and carries a black box warning for these side effects. In our study, we tested nilotinib in the concentration range from 0.1 to $15 \mu \mathrm{M}$ using in vitro rat cardiomyocyte cells (H9c2), commercially available myogenic cell lines derived from embryonic rat cardiac ventricle (Kimes and Brandt 1976). H9c2 cells show almost identical hypertrophic responses to those observed in primary cardiomyocytes and are usually utilized as in vitro model for studying the cardiotoxicity of drugs and agents (Watkins et al. 2011). Maximal plasma concentration in patients treated with nilotinib at a dose of $400 \mathrm{mg}$ twice daily was $4.27 \mu \mathrm{M}$ (Wolf et al. 2011). Clinically relevant doses of nilotinib led to an increased production of ROS, decreased cell viability and changes in cell morphology. Production of
Fig. 4. Changes in mitochondrial potential as a marker of mitochondrial dysfunction visualized using JC-1 reagent after 24-h treatment (A, upper row). Loss of the mitochondrial membrane potential is indicated by green fluorescence. Activation of caspase-3/7 after 24-h treatment as visualized using CellEvent ${ }^{\mathrm{TM}}$ Caspase3/7 Green Detection Reagent (A, lower row). Intensity of green fluorescence corresponds to amount of activated caspase-3/7 (B). Percentage of caspase-3/7-possitive cells after 24- and 48-h treatment with nilotinib. Fluorimetric evaluation of mitochondrial potential (C), number of apoptotic/ necrotic (D; black columns - apoptotic, spotted columns - necrotic), and TUNEL-positive (E) H9c2 cells after 24-h treatment with nilotinib. ${ }^{*} \mathrm{P} \leq 0.05$, ${ }^{* *} \mathrm{P} \leq 0.01$ using a two-tailed unpaired Student's t-test.
ROS has been identified as a mechanism of cardiotoxicity of many drugs, including carfilzomib, gefitinib or doxorubicin (Angsutararux et al. 2015). Stimulation of intrinsic mitochondrial apoptotic pathway by ROS and mitochondrial DNA damage promotes outer membrane permeabilization and mitochondria-to-cytosol translocation of cytochrome c, AIF or Smac/Diablo that trigger caspase-dependent or caspase-independent cytosolic signalling events (Ryter et al. 2007). Our results show the ability of nilotinib to affect mitochondrial membrane potential which is critical for maintaining the physiological function of the respiratory chain to generate ATP. Its significant loss renders cells depleted of energy with subsequent release of cytochrome $c$ and initiation of processes of apoptosis. This fact is in contrast to results published by Freeber and co-workers; the authors did not observed changes in mitochondria integrity after nilotinib treatment (Freebern et al. 2007). Apoptosis itself has been suggested to be an important contributor as apoptotic cardiomyocytes have been identified during hypoxia, ischemia, cardiac overload, acute myocardial infarction and end-stage heart failure (Arola et al. 2000). Nilotinib treatment led to a significant increase in the percentage of apoptotic cells, which is consistent with previous studies using diverse cell lines (Chen et al. 2016, Wolf et al. 2011). In addition, we determined the ability of nilotinib to induce ER stress. In this case, we 
observed enhanced expression of genes ATF4, CHOP and XBP1. Transcription factors ATF4 and CHOP are involved in the processes of formation, elongation and function of autophagosome, whereas XBP1 binds the mammalian ER stress-response element and is involved in cellular stress responses. The ability of nilotinib to induce ER stress was confirmed with enhanced protein aggregation. Optimum protein folding within the ER lumen requires ATP, $\mathrm{Ca}^{2+}$ and an oxidizing environment to allow disulphide bond formation (Gaut and Hendershot 1993). Possible changes in $\mathrm{Ca}^{2+}$ handling in nilotinibtreated cardiomyocytes due to ER stress may contribute to its cardiotoxic effect, too. However, this proposal needs further detailed studies. Hsp72 is a stress-inducible member of the Hsp70 family whose chaperoning activity is dependent on ATP (Young 2010). Enhanced expression of Hsp72 has been shown to reduce tissue injury in response to stress stimuli and improve cell survival in experimental models of stroke, sepsis, renal failure, and myocardial ischemia. In fact, Hsp72 overexpression leads to enhanced and prolonged XBP1 splicing during ER stress (Gorman et al. 2012). Gupta and co-workers have shown that Hsp72 enhances XBP1 mRNA splicing and expression of its target genes associated with attenuated apoptosis under ER stress conditions (Gupta et al. 2010). In the light of above mentioned facts, our results indicate the ability of nilotinib to induce ER stress. The connection between ER stress and apoptosis is still discussed. One of the characteristic features of ER stress is the increased expression of $C H O P$. Its induction is probably most sensitive to ER stress conditions where it plays a key role in ER stress-induced apoptosis that was observed in nilotinib-treated $\mathrm{H} 9 \mathrm{c} 2$ cells in our experiment (Gorman et al. 2012).

In conclusion, our results point to possible mechanisms of cardiotoxicity (and toxicity in general) of nilotinib. In addition, its ability to induce ER stress should be further investigated, especially with respect to co-treatments with pharmaceuticals affecting ER stress, e.g. beta-blockers, angiotensin receptor blockers (sartans) or GLP-1 agonists.

\section{Conflict of Interest}

There is no conflict of interest.

\section{Acknowledgements}

This work was supported by the project LQ1605 from the National Program of Sustainability II (MEYS CR) and by the project "Kardiovaskulární systém: od modelu přes terapii k prevenci" number MUNI/A/1365/2015 with the support of the Specific University Research Grant, as provided by the Ministry of Education, Youth and Sports of the Czech Republic in the year 2016.

\section{References}

ABBAS R, HUG BA, LEISTER C, SONNICHSEN D: A randomized, crossover, placebo- and moxifloxacin-controlled study to evaluate the effects of bosutinib (SKI-606), a dual Src/Abl tyrosine kinase inhibitor, on cardiac repolarization in healthy adult subjects. Int J Cancer 131: E304-E311, 2003.

ANGSUTARARUX P, LUANPITPONG S, ISSARAGRISIL S: Chemotherapy-induced cardiotoxicity: overview of the roles of oxidative stress. Oxid Med Cell Longev 2015: 795602, 2015.

AROLA OJ, SARASTE A, PULKKI K, KALLAJOKI M, PARVINEN M, VOIPIO-PULKKI LM: Acute doxorubicin cardiotoxicity involves cardiomyocyte apoptosis. Cancer Res 60: 1789-1792, 2000.

BERIAULT DR, WERSTUCK GH: Detection and quantification of endoplasmic reticulum stress in living cells using the fluorescent compound, Thioflavin T. Biochim Biophys Acta 1833: 2293-2301, 2013.

BONDON-GUITTON E, COMBRET S, PÉRAULT-POCHAT MC, STÈVE-DUMONT M, BAGHERI H, HUGUET F, DESPAS F, PATHAK A, MONTASTRUC JL: Cardiovascular risk profile of patients with peripheral arterial occlusive disease during nilotinib therapy. Target Oncol 11: 549-552, 2016.

CHEN T-C, YU M-C, CHIEN C-C, WU M-S, LEE Y-C, CHEN Y-C: Nilotinib reduced the viability of human ovarian cancer cells via mitochondria-dependent apoptosis, independent of JNK activation. Toxicol In Vitro 31: 1-11, 2016.

CORAZZARI M, LOVAT PE, ARMSTRONG JL, FIMIA GM, HILL DS, BIRCH-MACHIN M, REDFERN CPF, PIACENTINI M: Targeting homeostatic mechanisms of endoplasmic reticulum stress to increase susceptibility of cancer cells to fenretinide-induced apoptosis: the role of stress proteins ERdj5 and ERp57. Br J Cancer 96: 1062-1071, 2007. 
DEININGER M, BUCHDUNGER E, DRUKER BJ: The development of imatinib as a therapeutic agent for chronic myeloid leukemia. Blood 105: 2640-2653, 2005.

DOHERTY KR, WAPPEL RL, TALBERT DR, TRUSK PB, MORAN DM, KRAMER JW, BROWN AM, SHELL SA, BACUS S: Multi-parameter in vitro toxicity testing of crizotinib, sunitinib, erlotinib, and nilotinib in human cardiomyocytes. Toxicol Appl Pharmacol 272: 245-255, 2013.

FREEBERN WJ, FANG HS, SLADE MD, WELLS S, CANALE J, MEGILL J, GRUBOR B, SHI H, FLETCHER A, LOMBARDO L, LEVESQUE P, LEE FY, SASSEVILLE VG: In vitro cardiotoxicity potential comparative assessments of chronic myelogenous leukemia tyrosine kinase inhibitor therapies: dasatinib, imatinib and nilotinib. Blood 110: 4582-4582, 2007.

GAUT JR, HENDERSHOT LM: The modification and assembly of proteins in the endoplasmic reticulum. Curr Opin Cell Biol 5: 589-595, 1993.

GORMAN AM, HEALY SJM, JÄGER R, SAMALI A: Stress management at the ER: regulators of ER stress-induced apoptosis. Pharmacol Ther 134: 306-316, 2012.

GUPTA S, DEEPTI A, DEEGAN S, LISBONA F, HETZ C, SAMALI A: HSP72 protects cells from ER stress-induced apoptosis via enhancement of IRE1alpha-XBP1 signaling through a physical interaction. PLoS Biol 8: e1000410, 2010.

HAOUALA A, WIDMER N, DUCHOSAL MA, MONTEMURRO M, BUCLIN T, DECOSTERD LA: Drug interactions with the tyrosine kinase inhibitors imatinib, dasatinib, and nilotinib. Blood 117: e75-87, 2011.

HAZARIKA M, JIANG X, LIU Q, LEE S-L, RAMCHANDANI R, GARNETT C, ORR MS, SRIDHARA R, BOOTH B, LEIGHTON JK, TIMMER W, HARAPANHALLI R, DAGHER R, JUSTICE R, PAZDUR R: Tasigna for chronic and accelerated phase Philadelphia chromosome-positive chronic myelogenous leukemia resistant to or intolerant of imatinib. Clin Cancer Res 14: 5325-5331, 2008.

HE J, YAO J, SHENG HZ, ZHU JH: Involvement of the dual-specificity tyrosine phosphorylation-regulated kinase 1A-alternative splicing factor calcium/calmodulin-dependent protein kinase 118 signaling pathway in myocardial infarction-induced heart failure of rats. J Card Fail 21: 751-760, 2015.

JAFFRE F, BUSSEN M, FLOHRSCHUTZ I, MARTIN GR, ENGELHARDT S: Sprouty1 regulates cardiac homeostasis by negatively regulating the receptor tyrosine kinase pathways in heart. Cardiovasc Res 93: S95-S96, 2012.

JOHNSON FM, AGRAWAL S, BURRIS H, ROSEN L, DHILLON N, HONG D, BLACKWOOD-CHIRCHIR A, LUO FR, SY O, KAUL S, CHIAPPORI AA: Phase 1 pharmacokinetic and drug-interaction study of dasatinib in patients with advanced solid tumors. Cancer 116: 1582-1591, 2010.

KERKELÄ R, GRAZETTE L, YACOBI R, ILIESCU C, PATTEN R, BEAHM C, WALTERS B, SHEVTSOV S, PESANT S, CLUBB FJ, ROSENZWEIG A, SALOMON RN, VAN ETTEN RA, ALROY J, DURAND J-B, FORCE T: Cardiotoxicity of the cancer therapeutic agent imatinib mesylate. Nat Med 12: 908-916, 2006.

KIMES BW, BRANDT BL: Properties of a clonal muscle cell line from rat heart. Exp Cell Res 98: 367-381, 1976.

KONG JY, RABKIN SW: Palmitate-induced apoptosis in cardiomyocytes is mediated through alterations in mitochondria: prevention by cyclosporin A. Biochim Biophys Acta 1485: 45-55, 2000.

KRAUSE DS, VAN ETTEN RA: Tyrosine kinases as targets for cancer therapy. $N$ Engl J Med 353: 172-187, 2005.

KRIZANOVA O, STELIAROVA I, CSADEROVA L, PASTOREK M, HUDECOVA S: Capsaicin induces apoptosis in PC12 cells through ER stress. Oncol Rep 31: 581-588, 2014.

KUDO T, KANEMOTO S, HARA H, MORIMOTO N, MORIHARA T, KIMURA R, TABIRA T, IMAIZUMI K, TAKEDA M: A molecular chaperone inducer protects neurons from ER stress. Cell Death Differ 15: 364-375, 2008.

LAMBERT GK, DUHME-KLAIR A-K, MORGAN T, RAMJEE MK: The background, discovery and clinical development of BCR-ABL inhibitors. Drug Discov Today 18: 992-1000, 2013.

MOREIRA AC, BRANCO AF, SAMPAIO SF, CUNHA-OLIVEIRA T, MARTINS TR, HOLY J, OLIVEIRA PJ, SARDÃO VA: Mitochondrial apoptosis-inducing factor is involved in doxorubicin-induced toxicity on H9c2 cardiomyoblasts. Biochim Biophys Acta 1842: 2468-2478, 2014.

ORPHANOS GS, IOANNIDIS GN, ARDAVANIS AG: Cardiotoxicity induced by tyrosine kinase inhibitors. Acta Oncol 48: 964-970, 2009. 
RYTER SW, KIM HP, HOETZEL A, PARK JW, NAKAHIRA K, WANG X, CHOI AMK: Mechanisms of cell death in oxidative stress. Antioxid Redox Signal 9: 49-89, 2007.

SAWYERS CL: Opportunities and challenges in the development of kinase inhibitor therapy for cancer. Genes Dev 17: 2998-3010, 2003.

SAWYERS CL: Resistance to imatinib: more and more mutations. Blood 102: 4-5, 2003.

SHAH RR, MORGANROTH J, SHAH DR: Cardiovascular safety of tyrosine kinase inhibitors: with a special focus on cardiac repolarisation (QT interval). Drug Saf 36: 295-316, 2013.

SIRVENT A, BENISTANT C, ROCHE S: Cytoplasmic signalling by the c-Abl tyrosine kinase in normal and cancer cells. Biol Cell 100: 617-631, 2008.

TAKAHASHI S: Downstream molecular pathways of FLT3 in the pathogenesis of acute myeloid leukemia: biology and therapeutic implications. J Hematol Oncol 4: 4-13, 2011.

WATKINS SJ, BORTHWICK GM, ARTHUR HM: The H9C2 cell line and primary neonatal cardiomyocyte cells show similar hypertrophic responses in vitro. In Vitro Cell Dev Biol Anim 47: 125-131, 2011.

WEISBERG E, GRIFFIN JD: Mechanisms of resistance imatinib (STI571) in preclinical models and in leukemia patients. Drug Resist Updat 4: 22-28, 2001.

WOLF A, COUTTET P, DONG M, GRENET O, HERON M, JUNKER U, LEDIEU D, MAHL A, MARRER E, PERSOHN E, POGNAN F, ZHOU W, TSAO J, ROMAN D: Preclinical evaluation of potential nilotinib cardiotoxicity. Leuk Res 35: 631-637, 2011.

YANG B, PAPOIAN T: Tyrosine kinase inhibitor (TKI)-induced cardiotoxicity: approaches to narrow the gaps between preclinical safety evaluation and clinical outcome. $J$ Appl Toxicol 32: 945-951, 2012.

YOUNG JC: Mechanisms of the Hsp70 chaperone system. Biochem Cell Biol 88: 291-300, 2010. 